American Journal of Pharmaceutical Education 2018; 82 (7) Article 6636.

\title{
EDUCATION BRIEF
}

\section{Comparing Teaching Methods on Skin Disorders Using Standardized Patients Dressed in Moulage vs Paper Cases}

\author{
Emily K. Flores, PharmD, Rick Hess Jr., PharmD \\ Bill Gatton College of Pharmacy, East Tennessee State University, Johnson City, Tennessee \\ Submitted July 7, 2017; accepted March 9, 2018; published September 2018.
}

Objective. To determine whether using standardized patients dressed in moulage improves pharmacy students' ability to assess skin disorders compared to using picture-based paper cases. To determine pharmacy student preferences when learning assessment of skin disorders through these two educational methods.

Methods. Faculty members investigated student assessments of drug-induced skin disorders and contact dermatitis by using picture-based paper cases compared with using standardized patients dressed in moulage in a patient assessment course. Faculty members measured student knowledge via multiple-choice questions before laboratory, immediately after laboratory, and during a final examination 3 weeks later. Student preferences were measured immediately after laboratory via survey instrument in this randomized, non-blinded, crossover design educational study.

Results. No significant differences in knowledge scores related to skin disorders were found after laboratory or 3 weeks later when comparing the two educational methods. However, survey results suggested student preferences for using standardized patients dressed in moulage for drug-induced skin disorders. No significant differences were found for contact dermatitis cases.

Conclusion. Using standardized patients dressed in moulage did not improve pharmacy students' ability to assess skin disorders compared to using picture-based paper cases. Pharmacy students preferred standardized patients dressed in moulage only when learning assessment of drug-induced skin disorders.

Keywords: skin disorders, standardized patients, moulage, pharmacy student

\section{INTRODUCTION}

Colleges and schools of pharmacy are increasingly using different forms of active learning to teach patient assessment methods. ${ }^{1}$ These methods often include patient simulation in different forms; however, little research exists on the use of standardized patients (SPs) dressed in moulage. Moulage is the application of makeup and wax to mimic the appearance of a skin lesion, tumor, or other pathologic state. ${ }^{2}$ Simulation and standardized patients are defined elsewhere. ${ }^{3}$ Moulage has been used in the medical educational literature to teach assessment of skin disorders, most commonly in dermatology training and may be compared to utilization of written cases as a control. ${ }^{4-11}$ No research is openly available on utilization of SPs dressed in moulage to teach skin disorder assessment to pharmacy students.

Corresponding Author: Emily K. Flores, Bill Gatton College of Pharmacy, East Tennessee State University, Box 70657 , Johnson City, TN 37614-1704. Tel: 423-439-6754. Fax: 423-439-6784. E-mail: florese@etsu.edu
According to standard 2.1 of the 2016 American Council for Pharmacy Education accreditation standards and educational outcomes for pharmacy education, the graduate should be able to provide patient-centered care as the medication expert including collecting and interpreting evidence, prioritizing, formulating assessments and recommendations, implementing, monitoring and adjusting plans, and documenting activities. ${ }^{12,13}$ One area that pharmacists can practice many of these foundational skills at once is in assessment of skin disorders. In practice, pharmacists are expected to identify and respond to drug-induced skin disorders as part of the interprofessional team and are expected to identify, triage, and recommend self-care when appropriate for common skin disorders such as contact dermatitis. In the National Ambulatory Medical Care Survey (NAMCS) in 2013, diseases of skin and subcutaneous tissue were the primary diagnosis at office visits $4.2 \%$ of the time and skin rash was ranked 16th of the top 20 principal reasons for office visits in the population sampled. ${ }^{14}$ It is also estimated that between $12 \%$ and $31 \%$ of physician visits involve dermatological problems, depending on location, age, ethnicity, 


\section{American Journal of Pharmaceutical Education 2018; 82 (7) Article 6636.}

and type of provider. ${ }^{15}$ Pharmacists are routinely asked for assistance with many common skin conditions. ${ }^{15}$ This educational intervention was designed to study two specific categories of skin disorders likely encountered by community pharmacists: drug-induced skin disorders (DI) and contact dermatitis (CD).

This brief will focus on the design and assessment of a patient assessment course experience using picturebased paper cases and standardized patients dressed in moulage to assess skin disorders. The first objective of this study was to determine whether using SPs dressed in moulage improves pharmacy students' ability to assess skin disorders compared to using picture-based paper cases. The second objective was to determine pharmacy student preferences when learning assessment of skin disorders. The hypothesis was that the moulage-based cases would improve student ability to assess skin disorders compared to paper-based cases and be preferred by pharmacy students. Student ability was assessed using multiple-choice questions and preferences were assessed via survey instrument.

\section{METHODS}

Patient assessment is a course in the third-professional year (P3) involving a 50-minute lecture with a 90-minute laboratory component immediately thereafter. Students attended a didactic lecture on skin disorders that covered two general topics - drug-induced (DI) skin disorders and skin conditions that may be encountered in a community pharmacy setting, including contact dermatitis (CD). Immediately after the lecture, a multiple-choice quiz was administered to measure baseline knowledge prior to the laboratory. The questions were written and reviewed by the lecturer and course coordinator. Six questions (three questions on DI and three on $\mathrm{CD}$ ) were used to measure knowledge before and after laboratory and 3 weeks later for short-term knowledge retention. For the pre- and postlaboratory knowledge assessment, students were allowed 10 minutes to complete the quiz and their scores did not contribute to any graded portion of the laboratory exercise. The same six questions were included as part of the course's final examination, which occurred per semester schedule 3 weeks later. Knowledge was measured as the mean number of questions answered correctly and compared at each interval to examine whether the laboratory experience improved scores.

For the laboratory, students were randomly grouped in teams of five and assigned a total of four skin disorder cases. Two cases involved DI skin reactions with one characterizing an exanthematous drug eruption and the other a phototoxic reaction. The other two cases featured $\mathrm{CD}$ with differing severity (ie, mild and severe). To authenticate the skin reactions used in the laboratory, prelaboratory moulage was professionally applied to volunteers using the pictures from the picture-based paper cases as a guide. The skin areas were photographed and sent to at least three physicians practicing in family medicine, internal medicine and dermatology to review them for accuracy in clinical presentation. The physicians were invited to comment and rate the photographs using a 5-item Likert scale for validation. The feedback provided from this prelaboratory authentication step was used when applying moulage to SPs on the day of the laboratory. Images were previously presented in poster format. ${ }^{16}$

During laboratory, student teams had up to $20 \mathrm{~min}$ utes per case. Student groups started with two CD cases and half reviewed picture-based paper cases while the other half interviewed an SP dressed with CD-like moulage for the cases (Figure 1). Later in laboratory, the groups completed cases on DI skin disorders and half reviewed a picture-based paper case while the other half interviewed an SP dressed with DI-like moulage in

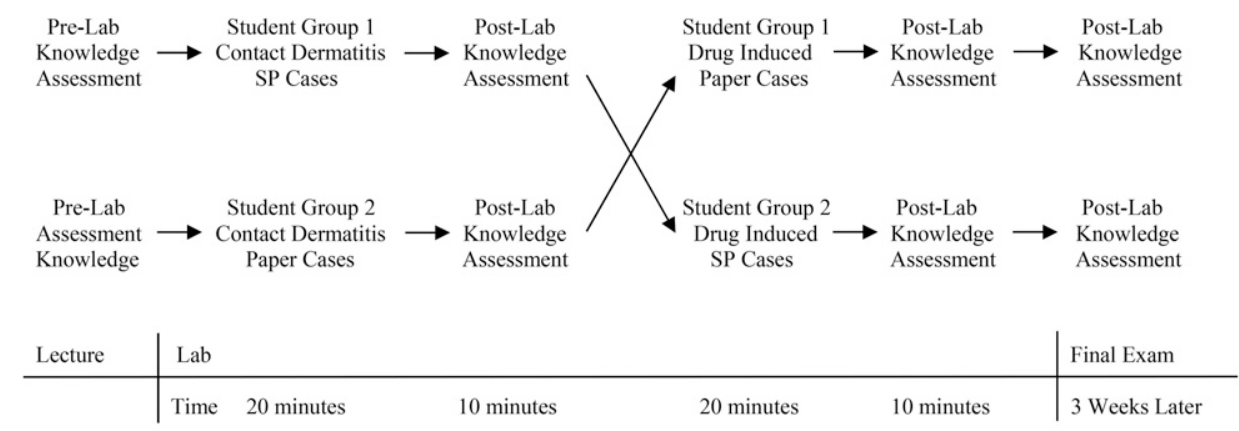

Students worked in groups of 5 for each case, but individual measurements of knowledge assessment and survey was obtained Knowledge assessment was measured before laboratory, after each case set and 3-week post-laboratory

Survey data was collected after each case

$\mathrm{SP}=$ Standardized Patient

Figure 1. Cross-Over Study Design. 


\section{American Journal of Pharmaceutical Education 2018; 82 (7) Article 6636.}

a cross-over design. Students were asked to identify the skin disorder present, determine the likely cause based on information provided, and make a recommendation to the patient that included a triage decision (self-care, physician visit, or emergent care) and any additional instructions they would provide. Students repeated the related quiz questions immediately after each set of cases, before switching.

The cases were identical except that the picturebased paper cases included the patient information and pictures of the patient (the previous standard of using open access images) while students in the SP arm conducted interviews of the SP dressed in moulage who answered questions using a case-specific script (new opportunity). The teams interviewing the SP had access to case information (ie, medication profile) but not the pictures. Before switching, each student individually answered three multiple choice quiz questions based on the category of skin disorder they had encountered in that half of laboratory (eg, DI or CD case) and completed a brief survey. The investigators created the survey instrument to measure and compare student confidence in assessing skin disorders, application to community pharmacy practice and satisfaction with the learning experience. The category specific knowledge assessment and survey instrument was repeated at the conclusion of laboratory after the students experienced the other category of skin disorder in the alternate format.

Student participation in completing the survey served as consent to study participation. Changes in post-laboratory and final scores compared with pre-laboratory knowledge scores was analyzed using an independent $t$-test and the Mann Whitney U test was used to compare paper and moulage student survey responses. A $p$ value of $<.05$ was set for statistical significance $a$ priori. All statistical analysis was performed using SPSS version 22 (IBM, Armonk, NY). The ETSU/VA Medical Campus Institutional Review Board approved the study.

\section{RESULTS}

Eighty students were enrolled in the course. Eightyeight percent of enrolled students $(n=70)$ attended lecture and completed the pre-laboratory knowledge assessment. Score analysis showed average scores ranging from $75 \%$ to $88 \%$ and a point biserial range of 34 to .42 . No significant differences were found in DI and CD knowledge scores whether the students were given paper or moulage techniques for either the post-laboratory or the final examination intervals (Table 1).

The survey response rate was $99 \%(n=79)$. Most responders were female (59\%) and the average age was 26 years. Most students (72\%) reported they worked in

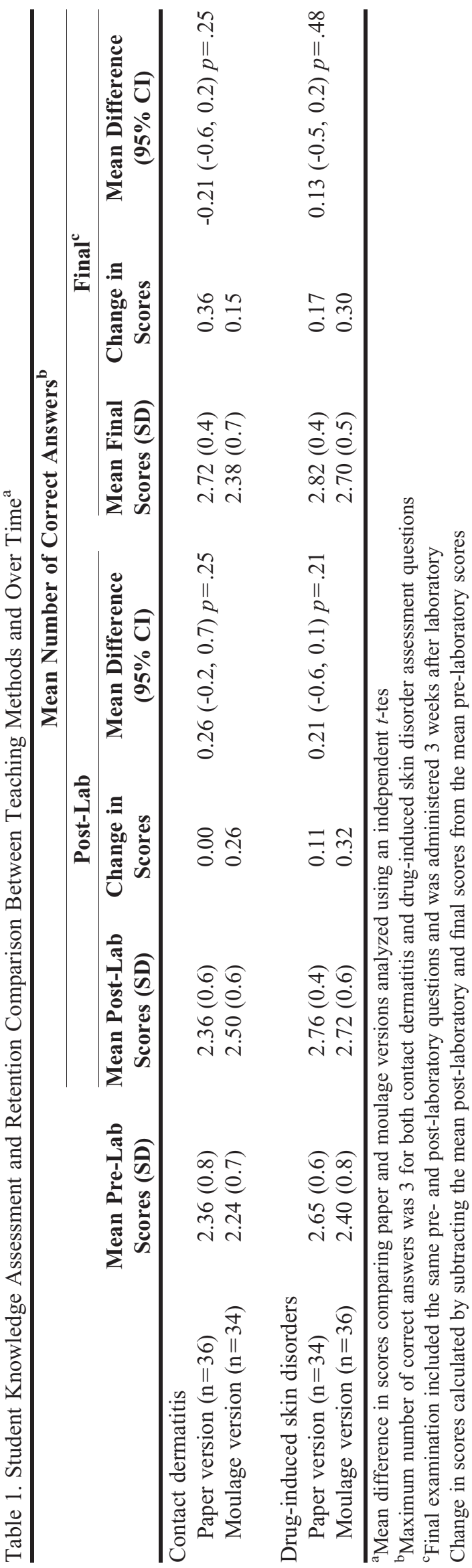




\section{American Journal of Pharmaceutical Education 2018; 82 (7) Article 6636.}

a community pharmacy at a mean of 6.6 hours per week. There were no significant differences in age, gender, community pharmacy experience, or hours worked between groups when analyzed separately. Significant differences were found in comparing the DI cases but not the CD cases (Table 2). Students were more satisfied with using SPs dressed in moulage as an instructional method for learning DI skin disorders as compared to paper cases $(p=.001)$ for DI cases only. Students were more confident in their ability to apply what was learned for DI skin disorders to community pharmacy settings after interacting with SPs dressed in moulage than paper cases $(p=.03)$. However, no significant difference was found when comparing satisfaction levels regarding CD cases. There were no other significant differences in student perception or confidence levels found in identifying,

Table 2. Survey Results Regarding Pharmacy Student Preferences for Skin Disorders Teaching Method (N=76)

\begin{tabular}{|c|c|c|c|c|c|c|}
\hline \multirow[b]{2}{*}{ Survey Item } & \multicolumn{3}{|c|}{ Drug-Induced Cases Survey Results } & \multicolumn{3}{|c|}{ Contact Dermatitis Cases Survey Results } \\
\hline & $\begin{array}{c}\text { Paper Case } \\
\text { Median (IQR) }\end{array}$ & $\begin{array}{l}\text { SP with Moulage } \\
\text { Median (IQR) }\end{array}$ & $p$ value $^{\mathrm{a}}$ & $\begin{array}{c}\text { Paper Case } \\
\text { Median (IQR) }\end{array}$ & $\begin{array}{l}\text { SP with Moulage } \\
\text { Median (IQR) }\end{array}$ & $p$ value $^{\mathrm{a}}$ \\
\hline $\begin{array}{l}\text { I understand assessment of } \\
\text { the skin disorder presented } \\
\text { in this case better after } \\
\text { having completed it. }\end{array}$ & $4(3,4)$ & $4(3,4)$ & .21 & $4(3,4)$ & $4(3,5)$ & .97 \\
\hline $\begin{array}{l}\text { The method of instruction } \\
\text { used in this case was } \\
\text { satisfactory for the skin } \\
\text { disorder presented in this } \\
\text { case. }\end{array}$ & $4(3,4)$ & $4(4,5)$ & .01 & $4(4,4)$ & $4(3,5)$ & .98 \\
\hline $\begin{array}{l}\text { I will be able to apply what I } \\
\text { learned through this case } \\
\text { when presented with } \\
\text { similar patients in } \\
\text { a community pharmacy. }\end{array}$ & $4(3,4)$ & $4(4,5)$ & .03 & $4(4,4)$ & $4(4,5)$ & .59 \\
\hline $\begin{array}{l}\text { The method of instruction } \\
\text { used in this case is } \\
\text { satisfactory to facilitate } \\
\text { my learning of the } \\
\text { material in this case. }\end{array}$ & $3(3,4)$ & $4(4,5)$ & .01 & $4(4,4)$ & $4(3,5)$ & .19 \\
\hline $\begin{array}{l}\text { I am confident in my ability } \\
\text { to correctly identify the } \\
\text { skin disorder covered in } \\
\text { this case in future patients. }\end{array}$ & $4(3,4)$ & $4(3,4)$ & .40 & $4(3,4)$ & $4(4,4)$ & .11 \\
\hline $\begin{array}{l}\text { I am confident in my ability } \\
\text { to correctly assess the } \\
\text { severity of the skin } \\
\text { disorder covered in this } \\
\text { case in future patients. }\end{array}$ & $4(4,4)$ & $4(4,4)$ & .76 & $4(3,4)$ & $4(4,4)$ & .22 \\
\hline $\begin{array}{l}\text { I am confident in my ability } \\
\text { to correctly triage the skin } \\
\text { disorder covered in this } \\
\text { case in future patients. }\end{array}$ & $4(3,4)$ & $4(3,4)$ & .36 & $4(3,4)$ & $4(4,5)$ & .12 \\
\hline
\end{tabular}

Abbreviations: $\mathrm{SP}=$ Standardized Patient, $\mathrm{IQR}=$ Interquartile Range

Likert Scale range: $0=$ strongly disagree to $5=$ strongly agree

${ }^{a}$ Mann Whitney U test used to compare median responses 


\section{American Journal of Pharmaceutical Education 2018; 82 (7) Article 6636.}

assessing or triaging skin disorders when comparing the two methods. Student rankings revealed they preferred learning by SPs dressed in moulage highest followed by lecture and then paper cases.

\section{DISCUSSION}

In designing this educational experience, it was hypothesized that the moulage-based cases would improve student ability to assess skin disorders and be preferred by students. This simulation teaching method could be a promising way to bring more realistic patient cases into the learning environment if found to be available, effective, acceptable, and affordable for the pharmacy school. The use of SPs has already been demonstrated as a reasonable active learning method; however, common drawbacks in the health professional literature include access to well-trained SPs, cost, and unclear educational benefit beyond conventional education strategies. ${ }^{3,17-20}$ The use of SPs in teaching has been generally well received by pharmacy students. ${ }^{3,17,21-23}$ To the authors' knowledge, this is the first study to investigate SPs dressed in moulage in pharmacy education. However, the use of SPs vs. paper cases has been examined before with similar findings related to improved knowledge pre- to post- with both intervention types without clear differences. ${ }^{22}$ The findings also confirm that using SPs did not significantly improve student knowledge of skin disorders compared with paper cases.

The knowledge scores indicate students were able to learn about skin disorders and retain knowledge equally using both methods. While there was no significant improvement in knowledge scores between either method, students are more satisfied with learning using SPs than paper cases.

Using SPs carries a cost per SP per hour, which varies depending on the type of learning environment and level of SP training. Using SPs also requires space for the interaction. Make-up artists who are skilled in applying the moulage well are not widely available. The cost of using SPs may outweigh the benefits for programs. Programs would require access to these resources and the funds to use the resources. Programs would also need to determine whether this topic is a worthwhile stewardship of time, space, and resources. The utilization of SPs dressed in moulage for this laboratory experience cost $\$ 518.50$. This cost included professional make-up application done by two people with significant background in costume design, stage make-up, moulage, body paint, and prosthetic construction. One of the moulage artists is the coordinator of the SP program and did not charge for her time spent in moulage application as she holds a salaried position. The SPs were paid an hourly wage for their time spent in the exercise and applying the moulage. Since this laboratory session, this college has begun paying SPs for time spent learning new cases, which was not included in the initial cost. SPs have significant training in communication skills and complete a physical examination when they are hired into the program and periodically. The coordinator of the SP program who is employed by this school's college of medicine oversees the program.

Students believe that using SPs dressed in moulage helped facilitate their learning about DI skin disorders better than paper cases. They also believe that they will be able to apply their learning in community-based practice more than what they would have learned from paperbased cases. The reasons for the difference are unknown. One possible explanation is that the incidence of CD observed by the community pharmacist may be more common than DI skin disorders, so perhaps the example of skin-disorders chosen by the investigators played a more significant role than expected. Seventy-two percent of students had community pharmacy experience and may have already encountered patients with $\mathrm{CD}$. Therefore, this condition may not be new to them anymore. The net benefit gained must be carefully weighed with the inherent higher costs associated with using SPs. As such, faculty members are encouraged to carefully decide when to use SPs for instruction and for which type of active learning activities SPs should be employed.

There are limitations to this study. First, the knowledge assessment was based only on six questions. While the questions appear discriminating based on point biserial values, they may have failed to thoroughly assess student knowledge of skin disorders presented in laboratory. Also, assessing students with multiple-choice questions may not truly reflect actual performance in practice. Second, while the pre-laboratory moulage was validated, modifications were made for the in-laboratory moulage based on physician feedback that was not reapplied, photographed and returned for a second review due to time constraints. Third, the mild and severe CD were grouped together and the exanthematous drug eruption and phototoxicity were grouped together in categories instead of reviewing the cases individually, which may have affected the results. Fourth, the SP interviews occurred within student teams and not individually so variations in information exchange were not fully controlled. Fifth, as a cross-over study in a timeconstrained educational environment, there was not a wash-out period between intervention types which may have limited intervention effectiveness. Finally, the survey instrument used to measure student perception and confidence levels was a non-validated instrument created by the investigators. 


\section{American Journal of Pharmaceutical Education 2018; 82 (7) Article 6636.}

\section{CONCLUSION}

Utilization of SPs dressed in moulage appears to be an acceptable method for educating pharmacy students on DI skin disorders. This method, however, is more costly than paper cases and may not have a clear benefit on student knowledge retention in the short term. Further research is needed to better assess if this translates to other skin disorders and to ascertain if there are long-term implications in the first few years of practice due to utilization of SPs dressed in moulage over paper-based cases. There are additional communication skills and information gathering skills that are used with the SP encounters that cannot be replicated on paper and the necessity of these skills is reflected in Standards 2.1 (Caregiver), 3.6 (Communicator), and 4.4 (Professional) of the 2016 American Council for Pharmacy Education accreditation standards and educational outcomes for pharmacy education as well as in this college's curricular learning outcomes. $^{12,13,24}$ This college will continue to use moulage in teaching portions of this material because of student satisfaction, availability of resources, and the ability to better emulate real-life scenarios often encountered in community pharmacy practice.

\section{ACKNOWLEDGMENTS}

The authors would like to thank Nick Hagemeier, PharmD, PhD and Ralph Lugo, PharmD for their assistance with statistical analysis, and to Ms. Perry Butler (SP Coordinator), the make-up artists and all standardized patients involved in the study. There was no external funding or support obtained for this study.

\section{REFERENCES}

1. Spray JW, Parnapy SA. Teaching patient assessment skills to doctor of pharmacy students: the TOPAS study. Am J Pharm Educ. 2007;71(4):Article 64.

2. Stedman's Medical Dictionary. 28th ed. Baltimore: Williams \& Wilkins; 2006. Moulage: 1229.

3. Vyas D, Bray BS, Wilson MN. Use of simulation-based teaching methodologies in US colleges and schools of pharmacy. Am J Pharm Educ. 2013;77(3):Article 53.

4. Jain N, Anderson MJ, Patel P, et al. Melanoma simulation model: promoting opportunistic screening and patient counseling. JAMA Dermatol. Jun 2013;149(6):710-716.

5. Hernandez C, Mermelstein R, Robinson JK, Yudkowsky R. Assessing students' ability to detect melanomas using standardized patients and moulage. J Am Acad Dermatol. Mar 2013;68(3): e83-e88.

6. Goulart JM, Dusza S, Pillsbury A, Soriano RP, Halpern AC, Marghoob AA. Recognition of melanoma: a dermatologic clinical competency in medical student education. J Am Acad Dermatol. 2012;67(4):606-611.
7. Wanat KA, Kist J, Jambusaria-Pahlajani A, et al. Improving students' ability to perform skin examinations and detect cutaneous malignancies using standardized patients and moulage. J Am Acad Dermatol. 2013;69(5):816-817.

8. Tariq U, Sood M, Goodsman D. The facilitator's role in London's air ambulance's simulation "moulage" training. Air Med J. 2015;34(2):92-97.

9. Smith-Stoner M. Using moulage to enhance educational instruction. Nurse Educ. 2011;36(1):21-24.

10. Kuhrik M, Seckman C, Kuhrik N, Ahearn T, Ercole P. Bringing skin assessments to life using human patient simulation: an emphasis on cancer prevention and early detection. J Cancer Educ.

2011;26(4):687-693.

11. Atlas RM, Clover RD, Carrico R, Wesley G, Thompson M, McKinney WP. Recognizing biothreat diseases: realistic training using standardized patients and patient simulators. J Public Health Manag Pract. 2005;Suppl:S143-S146.

12. Accreditation Council for Pharmacy Education. Accreditation standards and key elements for the professional program in pharmacy leading to the doctor of pharmacy degree. Standards 2016. https:// www.acpe-accredit.org/pdf/Standards2016FINAL.pdf.

13. Medina MS, Plaza CM, Stowe CD, et al. Center for the Advancement of Pharmacy Education 2013 educational outcomes. Am J Pharm Educ. 2013;77(8):Article 162.

14. Hing E, Rui P, Palso K. National ambulatory medical care survey: 2013 state and national summary tables. http://www.cdc.gov/ nchs/ahcd/ahcd_products.htm. Accessed March 24, 2017.

15. Herrier RN, Apgar DA, Boyce RW, Foster SL. Common skin disorders. In: Herrier RN, Apgar DA, Boyce RW, Foster SL, eds. Patient Assessment in Pharmacy. New York, NY: McGraw-Hill; 2015.

16. Hess R, Flores EK. Comparison of teaching methods on skin disorders: standardized patients dressed in moulage versus paper cases [poster abstract]. Am J Pharm Educ. 2014;78():51-52.

17. Schultz KK, Marks A. Community-based collaboration with high school theater students as standardized patients. Am J Pharm Educ. 2007;71(2): Article 29.

18. Dull P, Haines DJ. Methods for teaching physical examination skills to medical students. Fam Med. 2003;35(5):343-348.

19. Crea KA. Practice skill development through the use of human patient simulation. Am J Pharm Educ. Nov 10 2011;75(9):188.

20. Fernandez R, Parker D, Kalus JS, Miller D, Compton S. Using a human patient simulation mannequin to teach interdisciplinary team skills to pharmacy students. Am J Pharm Educ. 2007;71(3):Article 51.

21. Rickles NM, Tieu P, Myers L, Galal S, Chung V. The impact of a standardized patient program on student learning of communication skills. Am J Pharm Educ. 2009;73(1):Article 4.

22. Ray SM, Wylie DR, Shaun Rowe A, Heidel E, Franks AS. Pharmacy student knowledge retention after completing either a simulated or written patient case. Am J Pharm Educ. 2012;76(5): Article 86.

23. Gallimore C, George AK, Brown MC. Pharmacy students' preferences for various types of simulated patients. Am J Pharm Educ. 2008;72(1):Article 4.

24. Directed Educational Aspirations and Markers of Success (DREAMS). In: Council F, ed: Gatton College of Pharmacy, East Tennessee State University; 2013. 